\title{
50 Years of Behavioral Science in mary de Groot Diabetes: A 2020 Vision of the Future
}

Diabetes Care 2021;44:633-640 | https://doi.org/10.2337/dci20-0058

This article is adapted from a speech Dr. de Groot delivered in June 2020 as President, Health Care \& Education, of the American Diabetes Association at the Association's 80th Scientific Sessions, which was held online as a result of coronavirus disease 2019. Dr. de Groot is an Associate Professor of Medicine in the Division of Endocrinology, Diabetes and Metabolism at Indiana University (IU) School of Medicine. She serves as the Acting Director of the IU Diabetes Translational Research Center. Dr. de Groot is the 2020 recipient of the Rachmiel Levine Medal for Leadership from the American Diabetes Association.

In the year 2020, we marked the 50th anniversary of the field of behavioral science in diabetes in the modern era. Over this relatively short period of time, this field has charted the psychosocial landscape of prediabetes and diabetes by establishing the prevalence and impact of emotional and behavioral aspects of diabetes. Interventions to address these conditions have been developed that span the T2 to T4 translational research spectrum ranging from the intrapsychic to population-based interventions. Policies ranging from standards of care to Medicare benefits have been implemented. A review of research in the area of diabetes and depression is provided as an example of innovations in this field. Behavior is the foundation of all interventions we make in diabetes and prediabetes. As a mature science, it is critical to stemming the tide of diabetes and its outcomes. To make additional strides, we must rebalance our focus and augment funding for behavioral interventions for individuals, communities, and health care systems in conjunction with other forms of treatment.

When my presidential term began in January 2020, I never imagined that the 80th Scientific Sessions of the American Diabetes Association (ADA), where I would deliver my presidential address, would be our first ever virtual Scientific Sessions or that I would be seeing all of my patients in my clinical practice on virtual platforms. Thanks to coronavirus disease 2019 (COVID-19), we have all made tremendous pivots in the way we do everything - clinical care, research, and even the way we interact at professional conferences like our Scientific Sessions.

This year, we mark 50 years of behavioral science in diabetes in the modern era. I would like to share with you a portion of my experience with diabetes and a sample of the many milestones of the remarkable journey of this field.

Growing up in my family, there was never a time when I did not know the word "diabetes." The disease has played a formative role in the lives of three generations of my family, affecting my maternal grandmother, my mother, my brother, and me. My mother, Patricia, and her older sister Julianne were born in Sacramento, California, before the U.S. entered into World War II. My grandfather worked for the State of
Division of Endocrinology and Metabolism, Department of Medicine, Indiana University School of Medicine, Indianapolis, IN

Corresponding author: Mary de Groot, mdegroot@ iu.edu

This Presidential Address is also being published in Diabetes Spectrum Vol. 34, Issue 1, 2021.

(c) 2021 by the American Diabetes Association. Readers may use this article as long as the work is properly cited, the use is educational and not for profit, and the work is not altered. More information is available at https://www.diabetesjournals .org/content/license. 
California printing office, and my grandmother was a homemaker. My mother and Julianne enjoyed a happy early childhood. In 1943, at the age of 10 years, Julianne became unexpectedly ill, slipping into a diabetic ketoacidosis coma before the family doctor could be called. More than 50 years later, my grandmother could still describe the sugar crystals that formed inside the toilet bowl from Julianne's polyuria. Although Julianne was hospitalized and treated with high doses of insulin, she tragically died of cerebral and pulmonary edema hours after my grandparents left her hospital bedside. Julianne died of undiagnosed type 1 diabetes.

The legacy of Julianne's death left an indelible mark on three generations in my family. For my grandmother, there was lifelong complicated bereavement, severe depression, and unrelenting selfblame for "failing" to recognize the symptoms of diabetes that were not widely known at that time. For my mother, bearing witness to the loss of her only sibling left her with the burden of survivorship, growing up in the impossible shadow of what her sister "would have become" at each of her own developmental milestones and many life accomplishments.

For me, the legacy of this loss became a mandate of conscience: to devote my energy to improving life with diabetes and to lessen the physical and emotional pain associated with type 1 and type 2 diabetes. For my brother Michael and me, it also represented a genetic risk factor. For Michael, that risk factor eventually tipped the scales for the development of his type 2 diabetes. He now walks the all-too-familiar journey of coping with the daily demands of this disease. Fortunately, he does not walk alone. My sister-in-law Kristin, nephew Nathan, and niece Josephine are there to support him. As a family, they have had to learn how to avoid becoming the "diabetes police" by asking him how they can provide support that is truly helpful to him. As his sister, that applies to me, too. The journey of caring for diabetes has also been shared by my partner Brad and his sister Freya. Freya was diagnosed with type 1 diabetes at the age of 13 years and bravely managed her diabetes and its complications for nearly 55 years.

I share this personal story not simply because it is a story about people I love but because it mirrors the psychosocial landscape of diabetes that affects 34.2 million adults, children, and families in the U.S. (1). Themes of loss associated with the course of diabetes, adjustment to diagnosis, the enduring and changing impact of diabetes on the lives of patients, parents, and siblings, the critical role of social support, and experiences of depression and diabetes distress apply, in some measure, to everyone affected by diabetes. These themes are also central to the modern history of behavioral science in diabetes.

\section{A BRIEF HISTORY OF 50 YEARS OF BEHAVIORAL SCIENCE IN DIABETES}

The terms we use to describe this aspect of science in diabetes have evolved over time, just as our understanding of the complexities of living with diabetes has grown. The first term that applies to this field is "behavioral science." Whitley and Kite (2) have defined it as being "composed of three interrelated aspects: research that generates knowledge, theory that organizes knowledge, and application that puts knowledge to use" (2). While still applicable, this term has since broadened to incorporate a continuum of research that spans from understanding mechanisms of action in biopsychosocial phenomena (phase $\mathrm{T} 2$ translational research) to the evaluation of interventions in their target environments through effectiveness studies (T3) to population health and implementation science (T4) (Fig. 1) (3).

As our definitions have grown, so too has the range of expertise that has been brought to bear on these intricate problems. The T2-T4 diabetes translational workforce is diverse, spanning many disciplines, scientific traditions, and areas of expertise, including social scientists, psychologists, nurses, dietitians, pharmacists, epidemiologists, physicians, social workers, occupational and physical therapists, and others. In short, this group includes everyone who is interested in how our patients think and feel and what they do.

Our methods are equally diverse. We use mixed methodologies that allow us to hear the voices of people with diabetes and, from these voices, measure constructs that capture many of the facets of the lived experience of this set of diseases.

When I first began working in diabetes in 1991, with Alan Jacobson at the Joslin Diabetes Center, one of the first articles I read was "The Myth of the Diabetic
Personality," written by John Turtle and Stewart Dunn and published in Diabetes Care in 1981 (4). This article called into question the pervasive clinical attributions, dating back to Menninger in 1935 (5), that people with diabetes were imbued with a "diabetic personality," defined as being difficult, uncooperative, and demanding. What had supported this impression? Patients with diabetes asked questions of their health care providers, they did not settle for simple answers, and they frequently needed more time than the typical clinical encounter allowed. They also struggled with recommendations for diabetes selfmanagement and frequently fell short of clinical expectations for self-care. Dunn and Turtle (4) critically evaluated the evidence for these clinical attributions using early meta-analytic methodology and advocated for the empirical evaluation of the many psychosocial facets of the lived experience of diabetes. They called for methodologically rigorous behavioral science that made careful comparisons of psychological experiences of people with and without diabetes.

This year, we mark 50 years of discovery, measurement, and innovation in behavioral science in the modern era. In this relatively short time, three generations (and growing) of behavioral scientists have developed and used rigorous qualitative and quantitative research methodologies to characterize the psychosocial and emotional landscapes of type 1 and type 2 diabetes. The progression of this science has been systematic. We began with phenomenology, using qualitative data to listen closely to these experiences, and then we developed measures that accurately and reliably access the constructs of these experiences. From there, we began to link these constructs to others, searching for physiologic, environmental, and psychological correlates and potentially the causes of these experiences.

With measurement comes the development of interventions using study designs to rigorously test the intervention in its most pristine form. Once established, we adapt these interventions to multiple populations, conditions, and settings with the ultimate goal of bringing useful tools and approaches to improve the lives of everyone affected by diabetes. With these tools and data to support their efficacy and effectiveness 


\section{Clinical Translational Research Spectrum}

\begin{tabular}{|c|c|c|c|c|c|c|c|c|c|c|}
\hline 1 & T0.5 & & T1 & & T2 & & T3 & & T4 & \\
\hline $\begin{array}{c}\text { Basic } \\
\text { Scientific } \\
\text { Discovery }\end{array}$ & $\longleftrightarrow$ & $\begin{array}{l}\text { Preclinical } \\
\text { Insights }\end{array}$ & $\longleftrightarrow$ & $\begin{array}{l}\text { Clinical } \\
\text { Insights }\end{array}$ & $\rightleftarrows$ & $\begin{array}{l}\text { Implications } \\
\text { for Practice }\end{array}$ & 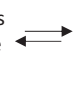 & $\begin{array}{l}\text { Implications } \\
\text { for Population } \\
\text { Health }\end{array}$ & $\rightleftarrows$ & $\begin{array}{l}\text { Improved } \\
\text { Global } \\
\text { Health }\end{array}$ \\
\hline & $\begin{array}{l}\text { Translatio } \\
\text { to Natura } \\
\text { nimal Mod }\end{array}$ & & $\begin{array}{l}\text { Translation } \\
\text { to Humans }\end{array}$ & & $\begin{array}{l}\text { Translatior } \\
\text { to Patient }\end{array}$ & & $\begin{array}{l}\text { Translatic } \\
\text { to Practi }\end{array}$ & & $\begin{array}{l}\text { anslation } \\
\text { Population }\end{array}$ & \\
\hline
\end{tabular}

Figure 1-Continuum of translational research. Adapted from Sussman et al. (3).

in hand, we have advanced to the level of policy, helping to shape the ADA's Standards of Medical Care in Diabetes. In 2016, I was privileged to work with Deborah Young-Hyman, Mark Peyrot, Felicia HillBriggs, Korey Hood, and Jeff Gonzalez in writing the landmark ADA position statement titled "Psychosocial Care for People
With Diabetes" (6), which summarized and drew upon the findings of $\sim 46$ years of psychosocial data to develop standards of care in this area.

As illustrated in Fig. 2, we know that the psychosocial landscape of diabetes is a dynamic interplay of the characteristics of individuals and progression of disease across the life course (6). Evidence has taught us that there is a continuum of experiences that range from adaptive responses to living with diabetes to experiences we would consider clinically impactful or constituting functional impairment. All providers have a role to play in screening, evaluating, and supporting adaptive emotional and behavioral responses to the ongoing course of diabetes. When impairment or interference in diabetes self-management is evident, referral to behavioral health providers for evaluation and treatment is indicated; these professionals can work interactively with patients, families, and other members of the health care team to address these conditions (7).

\begin{tabular}{|c|c|c|c|}
\hline & & Continuum of psychosocial issues and behaviora & health disorders in people with diabetes \\
\hline & & Nonclinical (normative) symptoms/behaviors & Clinical symptoms/diagnosis \\
\hline & $\begin{array}{l}\text { Behavioral health } \\
\text { disorder prior to } \\
\text { diabetes diagnosis }\end{array}$ & None & $\begin{array}{l}\text { - Mood and anxiety disorders } \\
\text { - Psychotic disorders } \\
\text { - Intellectual disabilities }\end{array}$ \\
\hline & $\begin{array}{l}\text { Diabetes } \\
\text { diagnosis }\end{array}$ & $\begin{array}{l}\text { Normal course of adjustment reactions, } \\
\text { including distress, fear, grief, anger, initial } \\
\text { changes in activities, conduct, or personality }\end{array}$ & - $\quad$ Adjustment disorders* \\
\hline 总 & $\begin{array}{l}\text { Learning diabetes } \\
\text { self-management }\end{array}$ & $\begin{array}{l}\text { Issues of autonomy, independence, and } \\
\text { empowerment. Initial challenges with self- } \\
\text { management demonstrate improvement with } \\
\text { further training and support }\end{array}$ & $\begin{array}{ll}\text { - } & \text { Adjustment disorders* } \\
\text { - } & \text { Psychological factors affecting } \\
& \text { medical condition** }\end{array}$ \\
\hline$\underbrace{0}_{00}$ & $\begin{array}{l}\text { Maintenance of } \\
\text { self-management } \\
\text { and coping skills }\end{array}$ & $\begin{array}{l}\text { Periods of waning self-management } \\
\text { behaviors, responsive to booster educational } \\
\text { or supportive interventions }\end{array}$ & $\begin{array}{l}\text { - } \text { Maladaptive eating behaviors } \\
\text { - } \quad \text { Psychological factors** } \\
\text { affecting medical condition } \\
\end{array}$ \\
\hline 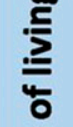 & $\begin{array}{l}\text { Life transitions } \\
\text { impacting disease } \\
\text { self-management }\end{array}$ & $\begin{array}{l}\text { Distress and/or changes in self-management } \\
\text { during times of life transition*** }\end{array}$ & 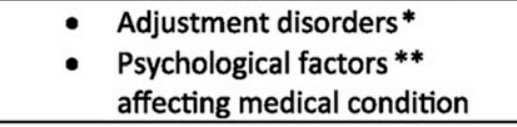 \\
\hline 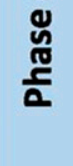 & $\begin{array}{l}\text { Disease } \\
\text { progression and } \\
\text { onset of } \\
\text { complications }\end{array}$ & $\begin{array}{l}\text { Distress, coping difficulties with progression } \\
\text { of diabetes/onset of diabetes complications } \\
\text { impacting function, quality of life, sense of } \\
\text { self, roles, interpersonal relationships }\end{array}$ & $\begin{array}{ll}\text { - } & \text { Adjustment disorders* } \\
\text { - } & \text { Psychological factors ** } \\
\text { affecting medical condition }\end{array}$ \\
\hline & $\begin{array}{c}\text { Aging and its } \\
\text { impact on disease } \\
\text { and self- } \\
\text { management }\end{array}$ & $\begin{array}{l}\text { Normal, age-related forgetfulness, slowed } \\
\text { information processing and physical skills } \\
\text { potentially impacting diabetes self- } \\
\text { management and coping }\end{array}$ & $\begin{array}{l}\text { - } \quad \text { Mild cognitive impairment } \\
\text { - Alzheimer or vascular } \\
\text { dementia }\end{array}$ \\
\hline & & $\begin{array}{l}\text { All health care team members (e.g., physicians, } \\
\text { nurses, diabetes educators, dieticians) as well } \\
\text { as behavioral providers } \\
\text { Providers for psychosocial and be }\end{array}$ & $\begin{array}{l}\text { Behavioral or mental health providers } \\
\text { (e.g., psychologists, psychiatrists, } \\
\text { clinical social workers, certified } \\
\text { counselors or therapists) } \\
\text { havioral health intervention }\end{array}$ \\
\hline
\end{tabular}

Figure 2-Continuum of psychosocial issues and behavioral health disorders in people with diabetes. Reprinted with permission from Young-Hyman et al. (6). *With depressed mood, anxiety, or emotion and conduct disturbance. **Personality traits, coping style, maladaptive health behaviors, or stress-related physiological response. ${ }^{* * *}$ Examples include changing schools, moving, job/occupational changes, marriage or divorce, or experiencing loss. 


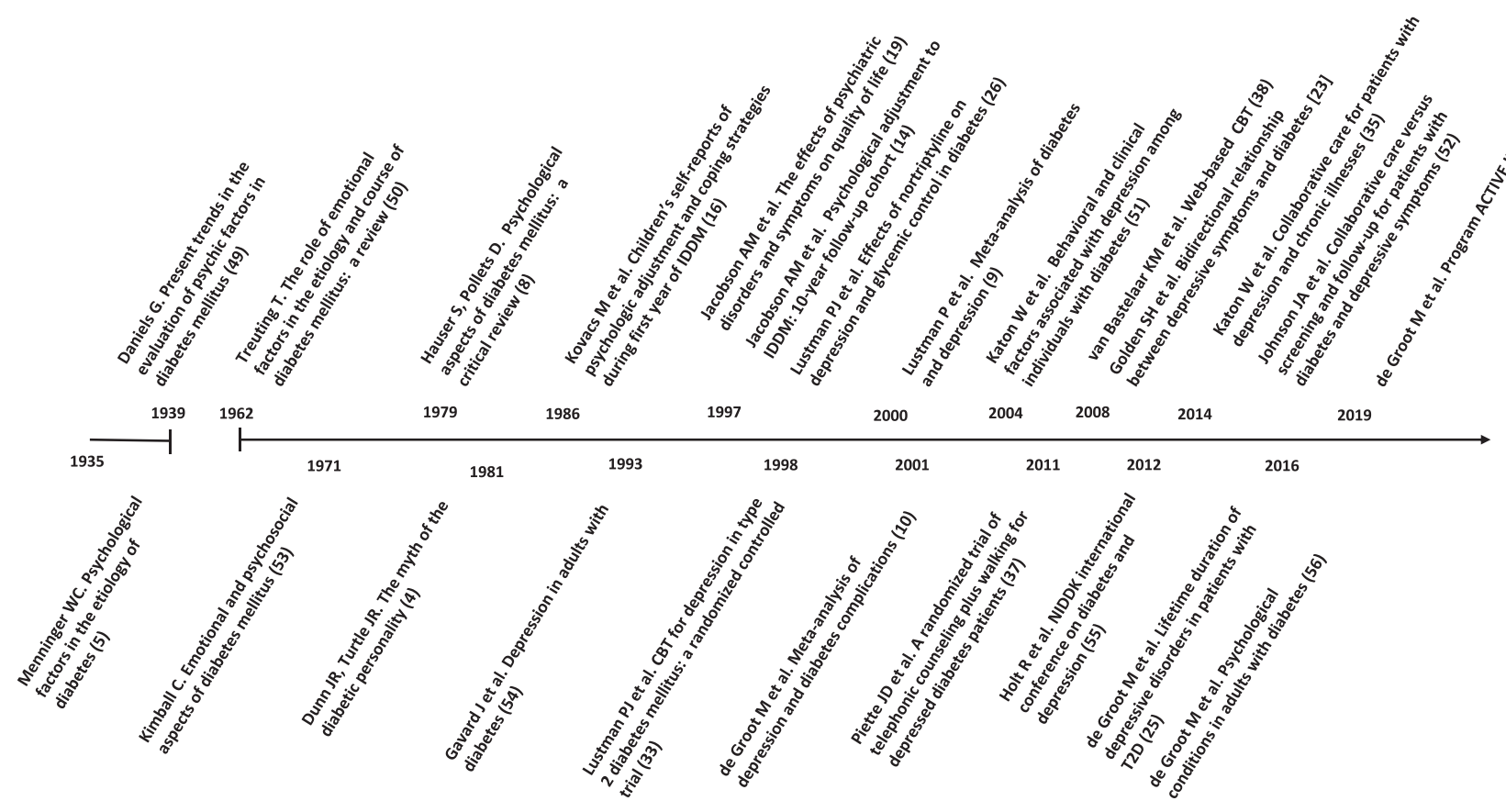

Figure 3-Timeline of scientific advances in diabetes and depression research.

In the past 50 years, we have characterized the nature and impact of depression, diabetes distress, anxiety, fear of hypoglycemia, challenges to adherence, and the crucial role of social support in managing type 1 or type 2 diabetes. Today, the ADA Standards of Care incorporate evaluation and treatment recommendations for the variety of psychosocial conditions that come with living with these diseases (7).

\section{DIABETES AND DEPRESSION: AN EXEMPLAR OF THE PROGRESSION OF BEHAVIORAL SCIENCE IN DIABETES}

Early research in diabetes and depression consisted of case studies and secondary data collected in clinical trials using depression screening measures (Fig. 3) $(8,9)$. Initial articles reporting depression outcomes for people with diabetes were not studies focused on this topic. However, a pattern across these studies began to emerge demonstrating that people with diabetes had elevated rates of depressive symptoms. We now know that elevated depressive symptoms affect one in four adults with type 1 or type 2 diabetes, and clinical depression affects one in eight people with diabetes (9).

The meta-analyses I performed with Pat Lustman, Ray Clouse, Ryan Anderson, and other colleagues $(9,10)$ helped to establish these rates, which have been borne out across multiple subsequent studies $(11,12)$. Work by Jacobson et al. (13-15) and Kovacs et al. $(16,17)$ documented elevated rates and correlates of depression in children with type 1 diabetes, as well as resilience among children and parents in coping with type 1 diabetes. Additional work documented the validity of depression screening measures in people with diabetes (18), the impacts of depression on quality of life in adults with type 1 or type 2 diabetes (19), and the relationship between depressive symptoms and diabetes complications $(10,20)$.

Another critical area has been to understand the onset and course of depression. Landmark work by Kawakami et al. (21), Eaton et al. (22), and Golden et al. $(23,24)$ established a bidirectional relationship between diabetes and depression. These studies demonstrated that a lifetime history of depression increases the risk for type 2 diabetes by $38 \%$ (23), in addition to the presence of diabetes increasing the risk of subsequent depression.

My own work has investigated the duration of major depressive episodes in adults with type 2 diabetes. My colleagues and I observed the duration of major depressive episodes to be 23 months compared with 18-22 weeks in adults in the general population (25). We have also confirmed that comorbid depression with diabetes is tenacious and chronic, showing that a single episode of depression increases the risk of developing subsequent episodes with the time between subsequent episodes becoming shorter (25).

Early intervention trials for the treatment of depression in diabetes focused on the viability of antidepressant medications in adults with diabetes (26-32). Lustman et al. (26) established that nortriptyline, a tricyclic antidepressant, is an effective treatment for depression with mild hyperglycemic effects. With the emergence of selective serotonin reuptake inhibitor (SSRI) antidepressants in the 1990s, clinical trials conducted by Lustman et al. and other research groups (27-32) established that SSRIs show comparable treatment effects to placebo with either euglycemic or slightly hypoglycemic effects.

Behavioral intervention trials for depression have expanded the tools and modes of treatment that are effective for people with diabetes. A 1998 randomized controlled trial of cognitive behavioral therapy (CBT) by Lustman et al. (33) established that CBT was superior to diabetes education for depression amelioration. 
Innovative work by Katon et al. $(34,35)$ at the University of Washington created the concept of collaborative care in the primary care setting, using a steppedcare approach for the identification and case management of diabetes and depression involving problem-solving therapy delivered by nurse case managers. Subsequent trials have tested the effectiveness of multiple delivery modalities to treat depression by expanding treatment sites beyond the walls of health care systems. These have included telephone-based CBT in combination with recommendations for regular walking, comparisons of CBT to SSRIs, and web-based CBT delivery (36-39).

My work has focused on leveraging resources for the treatment of depression and diabetes in partnership with community exercise and behavioral health providers. In the Program ACTIVE II study (40-42), a multistate randomized clinical trial, my team and I tested the comparative effectiveness of individual CBT, community-based exercise, and the concurrent delivery of these interventions against usual care. We found that both CBT and exercise were effective in the treatment of depression and improving psychosocial outcomes posttreatment. The combination of CBT and communitybased exercise over a 12-week period also yielded significant $A 1 C$ improvements in the majority subsample with a baseline A1C >7\% (42).

In the relatively short period of $\sim 50$ years, our scientific knowledge of depression in diabetes has advanced from clinical impressions to the development of large-scale interventions that are increasingly tailored for effective delivery across populations and settings. Depression is one of many psychosocial conditions affecting people with diabetes. This same progression has unfolded for many other conditions.

\section{THE FUTURE OF BEHAVIORAL SCIENCE}

In the ADA's 2016 position statement on psychosocial care (6), our writing team was intentional in creating guidelines that were prescriptive, based on existing evidence, and aspirational for the future. We posited that a key next step in the development of behavioral science in diabetes would be integrated care, an approach that synergistically leverages the expertise of multiple health care providers who treat and care for people with diabetes. Integrated care places the patient-provider relationship at the center of care, which is the milieu for assessment, medical decision-making, recommendations, and treatment implementation (Fig. 4) (43).

As we have moved through the COVID19 pandemic and advanced the largescale use of telehealth in recent months, we have all taken an unanticipated leap forward in innovations for the delivery of care. I would submit to you that, although our modality of connecting safely with patients has changed, the strength of our relationships with our patients, and with each other in the health care setting, is more fundamental than ever.

As the recently published sevenorganization joint consensus report on diabetes self-management education and support (DSMES) (43) rightly notes, the patient-provider relationship should be leveraged at key points in the course of this disease, including at diagnosis, annually, when complications develop or become exacerbated, and at times of life transition.

Another major area of needed work in the behavioral science of diabetes is the early identification of social determinants of health for diabetes prevention and diabetes treatment, paired with interventions that create an equitable playing field for preventing and thriving with diabetes (44). A crucial component of this work will involve eliminating the many forms of stigma that surround diabetes. The 2017 ADA/American Association of Diabetes Educators joint publication on the use of language in diabetes care and education (45) provided a landmark template for us all to follow to set the words and tone in our communication with our patients and, by so doing, reduce the cognitive traps that hinder successful self-care.

Another area of emphasis in the next 50 years of behavioral science in diabetes must be the continued development of a strong and vibrant workforce of researchers and clinicians. Here, we can borrow lessons from our bench science colleagues. Today, in T2-T4 diabetes translational research, we have an evolving set of largely ad hoc individual training programs across multiple institutions and fields. A systematic funding program is needed to provide the next generation of behavioral scientists with the training opportunities needed to integrate knowledge across disciplines and clinical care environments and to support settings in which they can use their talents and training.

\section{THE ADA'S EFFORTS TO ADVANCE BEHAVIORAL SCIENCE}

The ADA continues to advance programming and policy that affect all people at risk for and with diabetes. With regard to addressing health disparities and reducing stigma, the Association has joined the World Congress Weight Stigma Statement (46), the first international consensus statement to call for the ban of overweight and obesity stigma in all aspects of our societies. I was proud to represent ADA with 100 other organizations in the creation of this landmark statement. In July 2020, the ADA launched the \#HealthEquityNow initiative to create partnerships across community sectors to advance research, advocacy, and accessible interventions and thereby to break down the pillars of health disparities in diabetes. This initiative includes the creation of a Health Equity Bill of Rights for all people with diabetes (47).

The ADA has been leading efforts to understand and overcome challenges to treatment advancement through its Overcoming Therapeutic Inertia initiative. Hundreds of person-hours have been dedicated by ADA's professional volunteers, staff, and industry and community partners to characterize and target this pervasive phenomenon that poses key barriers to the timely advancement of all aspects of clinical care for diabetes. A white paper (48) recently published in Clinical Diabetes describes this effort and sets out the activities planned for and goals of this 3-year project.

Earlier this year, the ADA, in concert with six sister organizations, released the aforementioned 2020 consensus report on DSMES for people with type 2 diabetes (43). The adoption by all signatory organizations of the recommendations included in this report move us all toward greater integration of care.

Programmatically, ADA continues to lead access to diabetes prevention and care through the Diabetes Prevention Program, its Know Diabetes by Heart collaboration with the American Heart Association, and its Focus on Diabetes eye health initiative with partner organizations in the eye care arena. 


\section{FOUR CRITICAL TIMES FOR DIABETES SELF-MANAGEMENT EDUCATION AND SUPPORT SERVICES}

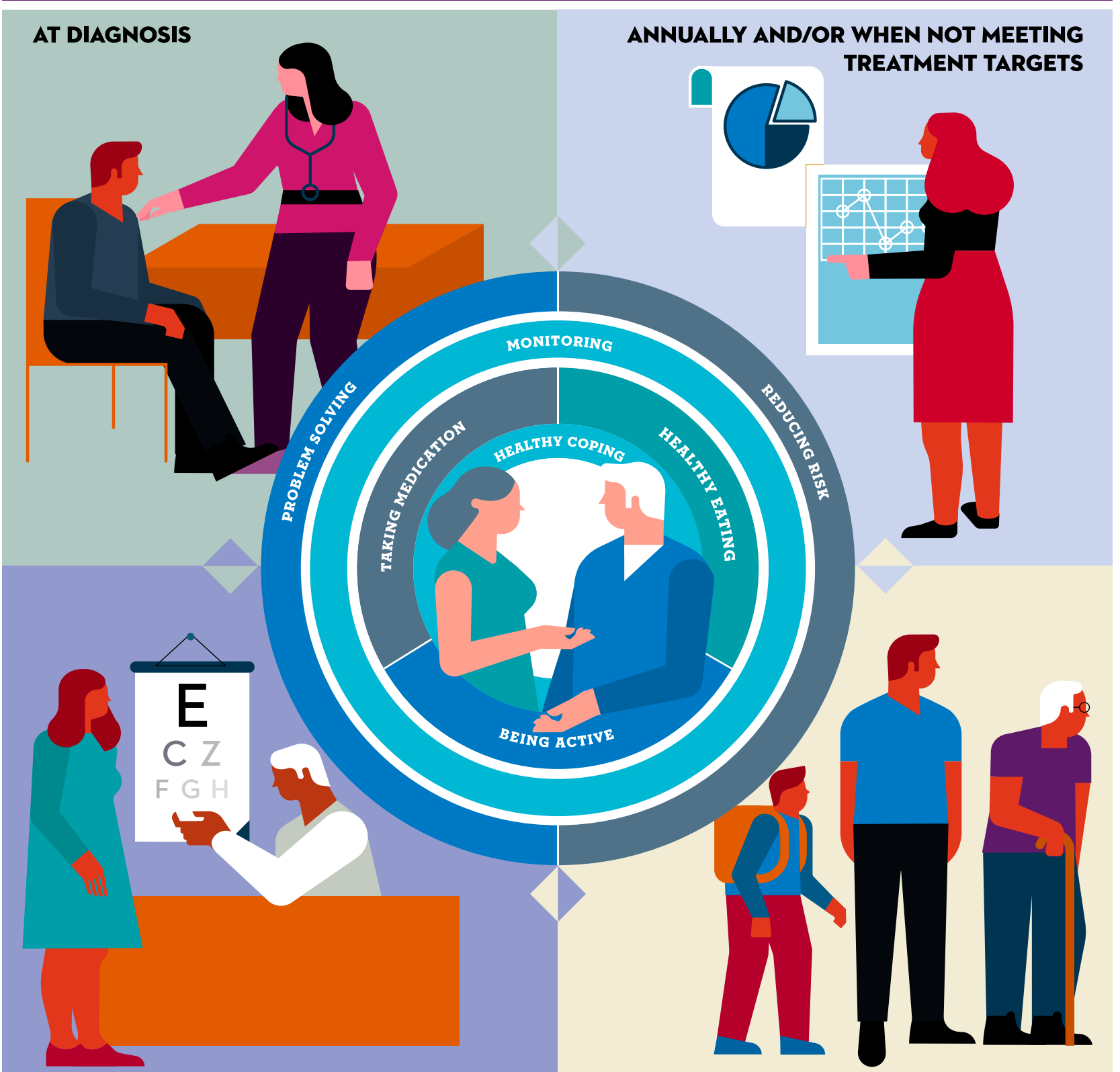

WHEN COMPLICATING FACTORS DEVELOP

WHEN TRANSITIONS IN LIFE AND CARE OCCUR

Figure 4-Person-centered care at the center of DSMES services. Reprinted with permission from Powers et al. (43).

I am proud to say that ADA has also collaborated with the American Psychological Association to create a Mental Health Provider Training Program designed to empower community mental health providers to understand and address the psychosocial landscape for children, families, and adults with diabetes. To date, this program has trained more than 450 psychologists, social workers, and allied mental health providers nationally. Graduates from this training program are entered into the ADA's National Mental Health Provider Directory, a searchable database for referrals by state.

\section{ADVOCACY}

During this COVID-19 pandemic, ADA worked effectively with the U.S. Centers for Medicare \& Medicaid Services (CMS) to advocate for the temporary approval of the use of continuous glucose monitoring (CGM) equipment during inpatient hospitalizations. Advocacy efforts are ongoing to reduce the administrative and behavioral barriers to qualifying for CGM use. The ADA has exerted its voice to advocate for the expansion of CMS reimbursement for DSMES and medical 
nutrition therapy services and to reduce patient and provider barriers to making use of these essential services. The Association also continues to advocate for the advancement of bipartisan legislation to control the cost of insulin.

\section{NEXT STEPS TOWARD THE NEXT GOLDEN AGE OF BEHAVIORAL RESEARCH IN DIABETES}

Recognizing that behavior is fundamental to everything we do in diabetes. we must embrace the reality that behavioral science is an equal partner to both medical innovation and interventions that we test, create, and implement. Fifty years ago, behavioral science in diabetes was in its infancy. Today, our science and tools must take their place alongside other disciplines at all levels of decisionmaking for diabetes-related funding, planning, and policy. Next, we must believe that we can effect change in the way we deliver care. If we build it, they will come. With this belief in mind, we need to secure funding for all aspects of this endeavor. With all of these elements in place, we can achieve fully integrated diabetes care that leverages all of our science to prevent diabetes before it starts and improves the lives of all people who have diabetes.

What does this goal require of us? First, we must practice our standards of care. I call on all diabetes care professionals to screen and refer patients for treatment of the psychosocial conditions that are endemic to diabetes. Second, we must be advocates for multidisciplinary teams at our institutions. Share what you know with decision makers and leaders at all levels. What we have to offer is crucial, not only to our patients, but also to our health care systems. During this time of economic flux, we must remind our leaders of our value. Third, we must support the funding of behavioral science research and programs. Finally, we must join ADA in advocating for improved access to affordable insulin, DSMES services, and CGM for our patients who stand to benefit from them.

Returning to the COVID-19 pandemic for a moment, there are many lessons we can learn from the impactful events the world has experienced in the past year. It is important to observe that our first line of defense against this new biological threat was changing behavior. Behavior, however variable and imperfect, has been our first and best strategy for keeping people safe: social distancing, hand washing, wearing protective masks and gloves, sheltering in place, and taking measure to quarantine when necessary. These behavioral tools were and continue to be the bedrock of public health in this time of COVID-19. Vaccines and medications will be a welcome next wave, but they will not replace this initial behavioral strategy. Rather, they represent a different set of therapies and behaviors that hold the potential to improve our health outcomes.

This lesson from COVID-19 also applies to diabetes. Behavior lies at the heart of every intervention we use in diabetes, whether it is making diet and physical activity changes to prevent diabetes or adding multiple medications and technologies to regulate metabolism in conjunction with healthy living to manage diabetes.

In 2021, we will mark the 100th anniversary of the discovery of insulin. We have much to celebrate with regard to this and other remarkable innovations that have transformed the lives of all people with diabetes in this century. It is insulin that would have saved Julianne's life had she been diagnosed in time. It has been the journey through innovations in insulin delivery that my sister-in-law, Freya, walked during more than 50 years with type 1 diabetes, as she moved from boiling syringes when first diagnosed to multiple daily injections.

Let us not forget that it is behavior that is the foundation of the success of every innovation in medications and devices. For patients, families, health care providers, and insurers, it is behavior that makes it possible for all new innovations to have an impact. As I like to share with my patients, medications only work if we take them. Devices only work if we use them. The time has come to recognize and celebrate the foundational role that behavior plays in all aspects of diabetes. In conjunction with other forms of treatment, behavioral science, as a mature discipline, is crucial to stemming the tide of diabetes and its negative outcomes for individuals, communities, and health care systems.

Acknowledgments. I wish to thank the many outstanding mentors and colleagues who have inspired, motivated, and nurtured me all along my professional journey. My first professional family was the Mental Health Unit at the Joslin Diabetes Center in Boston, MA: Alan Jacobson, Katie Weinger, Marilyn Ritholz, John Zrebeic, Barbara Anderson, and Bill Polonsky. Many thanks go to Laurie Ruggiero, who was my major professor at the University of Rhode Island. My years as a postdoctoral fellow at Washington University in St. Louis were shaped by Wendy Auslander, Patrick Lustman, and Ed Fisher. Thank you to my other wonderful peers and colleagues: Julie Wagner, Jeff Gonzalez, Korey Hood, Deborah Young-Hyman, Mark Peyrot, Felicia Hill-Briggs, Jay Shubrook, Yegan Pillay, Kieren Mather, members of the Diabetes Prevention Program Outcomes Study Group, and all of the members of the Behavioral Research in Diabetes Group Exchange.

I also wish to thank my ADA National Board of Director colleagues, past and present, starting with Richard Rubin, Liz Walker, David Marrero, Gretchen Youseff, and Felicia Hill-Briggs, who have been role models as past Presidents, Health Care \& Education. Thanks also to the team of principal officers and board members, together with Chief Scientific \& Medical Officer Robert Gabbay and Chief Executive Officer Tracey Brown, who leads us with energy, courage, and insight.

I also give thanks for my wonderful students, who continue to teach me about innovative thinking and learning. Thanks also to my Indiana University family: Tami Hannon, NiCole Keith, Jesse Stewart, Chandan Saha, Barb Myers, Rachel Klingensmith, Gina McAtee, Kisha Pinner, Mitch Smith, Patrick Stutz, my incredible colleagues at the Diabetes Translational Research Center, my division director Mike Econs, department chair Naga Chalasani, senior mentor Mark Geraci, and colleagues at the Indiana Diabetes Research Center, led by Carmella Evans-Molina.

I wish to thank my many patients and research participants who are our first and best teachers in understanding the psychosocial landscape of diabetes.

Most importantly, I wish to thank my parents, John and Patricia de Groot, for being loving and supportive roles models of lifelong learning and healthy living. I also thank my brother Michael, sister-in-law Kristin, nephew Nathan, and niece Josephine, who are the lights in my world. All my love and gratitude go to my partner Brad McCanless and my wonderful sons Cameron and Connor, whose belief and love have inspired and supported me when behavioral science and ADA board service have required early mornings, late dinners, and long nights. A special note of thanks goes to Brad, who rescued my laptop containing my speech from a black bear in the Smoky Mountains the day before I videotaped my address. You are my hero. Duality of Interest. M.d.G. is a faculty consultant to the Johnson \& Johnson Diabetes Institute, Inc. No other potential conflicts of interest relevant to this article were reported.

\section{References}

1. Centers for Disease Control and Prevention. National Diabetes Statistics Report, 2020. Atlanta, GA, Centers for Disease Control and Prevention, U.S. Department of Health and Human Services, 2020 2. Whitley BE, Kite ME. Principles of Research in Behavioral Science. 3rd ed. New York, Routledge, 2013

3. Sussman S, Valente TW, Rohrbach LA, Skara S, Pentz MA. Translation in the health professions: converting science into action. Eval Health Prof 2006;29:7-32

4. Dunn SM, Turtle JR. The myth of the diabetic personality. Diabetes Care 1981;4:640-646 
5. Menninger WC. Psychological factors in the etiology of diabetes. J Nerv Ment Dis 1935;81:1-13 6. Young-Hyman D, de Groot M, Hill-Briggs $F$, Gonzalez JS, Hood K, Peyrot M. Psychosocial care for people with diabetes: a position statement of the American Diabetes Association. Diabetes Care 2016;39:2126-2140

7. American Diabetes Association. Introduction: Standards of Medical Care in Diabetes-2020. Diabetes Care 2020;43(Suppl. 1):S1-S2

8. Hauser ST, Pollets D. Psychological aspects of diabetes mellitus: a critical review. Diabetes Care 1979;2:227-232

9. Lustman PJ, Anderson RJ, Freedland KE, de Groot M, Carney RM, Clouse RE. Depression and poor glycemic control: a meta-analytic review of the literature. Diabetes Care 2000;23:934-942 10. de Groot $M$, Anderson R, Freedland KE, Clouse RE, Lustman PJ. Association of depression and diabetes complications: a meta-analysis. Psychosom Med 2001;63:619-630

11. Mezuk B, Eaton WW, Albrecht S, Golden SH. Depression and type 2 diabetes over the lifespan: a meta-analysis. Diabetes Care 2008;31:2383-2390 12. Nouwen A, Adriaanse MC, van Dam K, et al.; European Depression in Diabetes (EDID) Research Consortium. Longitudinal associations between depression and diabetes complications: a systematic review and meta-analysis. Diabet Med 2019;36:1562-1572

13. Jacobson AM, Hauser ST, Cole C, et al. Social relationships among young adults with insulindependent diabetes mellitus: ten-year follow-up of an onset cohort. Diabet Med 1997;14:73-79 14. Jacobson AM, Hauser ST, Willett JB, et al. Psychological adjustment to IDDM: 10-year follow-up of an onset cohort of child and adolescent patients. Diabetes Care 1997;20:811-818

15. Jacobson AM, Hauser ST, Wertlieb D, Wolfsdorf JI, Orleans J, Vieyra M. Psychological adjustment of children with recently diagnosed diabetes mellitus. Diabetes Care 1986;9:323-329 16. Kovacs $M$, Brent $D$, Steinberg TF, Paulauskas $S$, Reid J. Children's self-reports of psychologic adjustment and coping strategies during first year of insulin-dependent diabetes mellitus. $\mathrm{Di}$ abetes Care 1986;9:472-479

17. Kovacs $M$, lyengar S, Goldston D, Stewart J, Obrosky DS, Marsh J. Psychological functioning of children with insulin-dependent diabetes mellitus: a longitudinal study. J Pediatr Psychol 1990; 15:619-632

18. Lustman PJ, Clouse RE, Griffith LS, Carney RM, Freedland KE. Screening for depression in diabetes using the Beck Depression Inventory. Psychosom Med 1997;59:24-31

19. Jacobson AM, de Groot M, Samson JA. The effects of psychiatric disorders and symptoms on quality of life in patients with type I and type II diabetes mellitus. Qual Life Res 1997;6:11-20 20. Cohen ST, Welch G, Jacobson AM, De Groot M, Samson J. The association of lifetime psychiatric illness and increased retinopathy in patients with type diabetes mellitus. Psychosomatics 1997;38:98-108 21. Kawakami N, Takatsuka N, Shimizu H, Ishibashi $\mathrm{H}$. Depressive symptoms and occurrence of type 2 diabetes among Japanese men. Diabetes Care 1999;22:1071-1076

22. Eaton WW, Armenian H, Gallo J, Pratt L, Ford DE. Depression and risk for onset of type II diabetes: a prospective population-based study. Diabetes Care 1996;19:1097-1102
23. Golden SH, Lazo M, Carnethon M, et al. Examining a bidirectional association between depressive symptoms and diabetes. JAMA 2008; 299:2751-2759

24. Golden SH, Williams JE, Ford DE, et al.; Atherosclerosis Risk in Communities study. Depressive symptoms and the risk of type $2 \mathrm{di}$ abetes: the Atherosclerosis Risk in Communities study. Diabetes Care 2004;27:429-435

25. de Groot M, Crick KA, Long M, Saha C, Shubrook JH. Lifetime duration of depressive disorders in patients with type 2 diabetes. Diabetes Care 2016;39:2174-2181

26. Lustman PJ, Griffith LS, Clouse RE, et al. Effects of nortriptyline on depression and glycemic control in diabetes: results of a doubleblind, placebo-controlled trial. Psychosom Med 1997:59:241-250

27. Lustman PJ, Freedland KE, Griffith LS, Clouse RE. Fluoxetine for depression in diabetes: a randomized double-blind placebo-controlled trial. Diabetes Care 2000;23:618-623

28. Gülseren L, Gülseren S, Hekimsoy Z, Mete L. Comparison of fluoxetine and paroxetine in type II diabetes mellitus patients. Arch Med Res 2005;36:159-165

29. Khazaie H, Rahimi M, Tatari F, Rezaei M, Najafi F, Tahmasian M. Treatment of depression in type 2 diabetes with fluoxetine or citalopram? Neurosciences (Riyadh) 2011;16:42-45

30. Lustman PJ, Williams MM, Sayuk GS, Nix BD Clouse RE. Factors influencing glycemic control in type 2 diabetes during acute- and maintenancephase treatment of major depressive disorder with bupropion. Diabetes Care 2007;30:459-466 31. Williams MM, Clouse RE, Nix BD, et al. Efficacy of sertraline in prevention of depression recurrence in older versus younger adults with diabetes. Diabetes Care 2007;30:801-806 32. Goodnick PJ, Kumar A, Henry JH, Buki VM, Goldberg RB. Sertraline in coexisting major depression and diabetes mellitus. Psychopharmacol Bull 1997;33:261-264

33. Lustman PJ, Griffith LS, Freedland KE, Kissel SS, Clouse RE. Cognitive behavior therapy for depression in type 2 diabetes mellitus: a randomized, controlled trial. Ann Intern Med 1998;129:613-621

34. Katon WJ, Von Korff M, Lin EH, et al. The Pathways Study: a randomized trial of collaborative care in patients with diabetes and depression. Arch Gen Psychiatry 2004;61:1042-1049

35. Katon WJ, Lin EH, Von Korff M, et al. Collaborative care for patients with depression and chronic illnesses. N Engl J Med 2010;363:2611-2620

36. Petrak F, Herpertz S, Albus C, et al. Cognitive behavioral therapy versus sertraline in patients with depression and poorly controlled diabetes: the Diabetes and Depression (DAD) study: a randomized controlled multicenter trial. Diabetes Care 2015;38:767-775

37. Piette JD, Richardson C, Himle J, et al. A randomized trial of telephonic counseling plus walking for depressed diabetes patients. Med Care 2011;49:641-648

38. van Bastelaar KM, Pouwer F, Cuijpers P, Riper H Snoek FJ. Web-based depression treatment for type 1 and type 2 diabetic patients: a randomized, controlled trial. Diabetes Care 2011;34:320-325

39. van der Feltz-Cornelis CM. Comorbid diabetes and depression: do e-health treatment achieve better diabetes control? Diabetes Manas (Lond) 2013;3:379-388
40. de Groot M, Doyle T, Averyt J. Program ACTIVE: cognitive behavioral therapy to treat depression in adults with type 2 diabetes in rural Appalachia. J Cogn Psychother 2017;31:158-170 41. Myers BA, Pillay Y, Guyton Hornsby W Jr, et al. Recruitment effort and costs from a multi-center randomized controlled trial for treating depression in type 2 diabetes. Trials 2019;20:621

42. de Groot M, Shubrook JH, Hornsby WG Jr, et al. Program ACTIVE II: outcomes from a randomized multistate community-based depression treatment for rural and urban adults with type 2 diabetes. Diabetes Care 2019;42:1185-1193

43. Powers MA, Bardsley JK, Cypress M, et al. Diabetes self-management education and support in adults with type 2 diabetes: a consensus report of the American Diabetes Association, the Association of Diabetes Care \& Education Specialists, the Academy of Nutrition and Dietetics, the American Academy of Family Physicians, the American Academy of PAs, the American Association of Nurse Practitioners, and the American Pharmacists Association. Diabetes Care 2020;43: 1636-1649

44. Thornton PL, Kumanyika SK, Gregg EW, et al. New research directions on disparities in obesity and type 2 diabetes. Ann N Y Acad Sci 2020;1461:5-24 45. Dickinson JK, Guzman SJ, Maryniuk MD, et al. The use of language in diabetes care and education Diabetes Care 2017;40:1790-1799

46. Rubino F, Puhl RM, Cummings DE, et al. Joint international consensus statement for ending stigma of obesity. Nat Med 2020;26:485-497

47. American Diabetes Association. \#HealthEquityNow. Accessed 20 November 2020. Available from https://www.diabetes.org/healthequitynow

48. Gabbay RA, Kendall D, Beebe C, et al. Addressing therapeutic inertia in 2020 and beyond: a 3-year initiative of the American Diabetes Association. Clin Diabetes 2020;38:371-381

49. Daniels GE.Present trends in the evaluation of psychic factors in diabetes mellitus. Psychosom Med 1939;1:527-551

50. Treuting TF. The role of emotional factors in the etiology and course of diabetes mellitus: a review of the recent literature. Am J Med Sc 1962:244:93-109

51. Katon W, von Korff M, Ciechanowski P, et al Behavioral and clinical factors associated with depression among individuals with diabetes. Diabetes Care 2004;27:914-920

52. Johnson JA, Al Sayah F, Wozniak L, et al. Collaborative care versus screening and followup for patients with diabetes and depressive symptoms: results of a primary care-based comparative effectiveness trial. Diabetes Care 2014; 37:3220-3226

53. Kimball CP. Emotional and psychosocial aspects of diabetes mellitus. Med Clin North Am 1971;55:1007-1018

54. Gavard JA, Lustman PJ, Clouse RE. Prevalence of depression in adults with diabetes: an epidemiological evaluation. Diabetes Care 1993, 16:1167-1178

55. Holt RI, de Groot M, Lucki I, Hunter CM, Sartorius N, Golden SH. NIDDK international conference report on diabetes and depression: current understanding and future directions. Diabetes Care 2014;37:2067-2077

56. de Groot M, Golden SH, Wagner J. Psychological conditions in adults with diabetes. Am Psychol 2016;71:552-562 